\title{
Paulo Duarte
}

\section{ERASMO GARCIA MENDES}

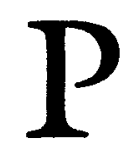

aulo Duarte nasceu em Sáo Paulo, no Bom Retiro, no dia 16 de novembro de 1899. Terminado o curso secundário, freqüentou por três anos o de medicina, mas acabou ingressando na Faculdade de Direito do Largo de São Francisco, tornando-se advogado. Em 1927, passou a fazer parte da redaçáo de $O$ Estado de São Paulo, ligandose filialmente a Júlio Mesquita, ocasiáo em que publicou seus primeiros livros Sob as Arcadas e Agora. Revelou-se, desde jovem, um espírito combativo e independente, empenhando-se em campanhas de caráter cívico-político e culturais. Filiado ao Partido Democrático, aderiu à Revoluçáo de $30 \mathrm{e}$, vitorioso o movimento, integrou o governo provisório estadual - conhecido como o goperno de 40 dias - chefiado por Francisco Morato. Desgostoso, como seus companheiros de jornada, com os rumos que Vargas imprimiu ao governo federal, postergando indefinidamente o retorno à plena legalidade e tratando São Paulo como território ocupado, Paulo Duarte participou das articulaçóes políticomilitares que resultaram na Revoluçáo Constitucionalista de 1932. Integrou inicialmente o Estado Maior do general Klinger, mas, logo, preferiu ir para a linha de frente, onde comandou o histórico trem blindado e foi ferido em combate. Consumada a derrota, tentou escapar com o coronel E. Figueiredo, sendo capturado em Santa Catarina.

Preso na célebre Sala da Capela, no Rio, com os demais líderes da revoluçáo, Paulo Duarte partiu com eles para o seu primeiro exflio político, em Portugal. Dessas suas aventuras resultaram dois livros, Palmares pelo avesso e Prisai, extlio e lutas. No regresso ao país, ingressou no Partido Constitucionalista - sucessór do Partido Democrático elegendo-se deputado estadual no pleito de 1934. Até 1937, quando se instalou o Estado Novo, Paulo Duarte foi consultor jurídico municipal e atuou na criaçáo do Departamento de Cultura da capital paulista. Sua lealdade aos princípios democráticos, consubstanciada no seu irrestrito apoio à cadidatura de Armando de Salles Oliveira à sucessão de Vargas, frustrada pelo golpe de 37, custou-lhe um segundo exilio, agora de nove anos, na França e nos Estados Unidos. Ao lado dessa militância política e administrativa, Paulo Duarte fez coexistir uma intensa atividade no campo da cultura. Foi um dos incentivadores da Semana de Arte Moderna de 22, autor do projeto de documentos históricos do Arquivo do Estado, um dos artífices da criaçáo do Conselho Bibliotecário e diretor 
do Museu Paulista. Como jornalista, foi redator não apenas de $O$ Estado de Sáo Paulo, mas também do extinto Didrio Nacional, órgão do Partido Constitucionalista.

Quando, durante a interventoria de Armando de Salles Oliveira, teve início o movimento do qual resultou a criaçáo da Universidade de São Paulo - entre 1933 e 1934 -, Paulo Duarte fez parte do entourage de Julio de Mesquita Filho, composta de expoentes da intelligentzia paulista para elaborar o projeto que materializaria a instituição. Seu propósito, provavelmente, incluía uma participação ativa quando a Universidade estivesse em pleno funcionamento, mas o novo exílio imposto pelo Estado Novo frustrou esse desejo.

Todavia, para a atividade que iria desenvolver no retorno do exílio, até que este lhe foi proveitoso em termos de aprimorar sua formação cultural. Primeiramente, na França, colaborou nas revistas $V u$ e $L u$ e, depois, ingressou no Musée de l'Homme, em Paris, dirigido por Paul Rivet, aperfeiçoando-se em Pré-História, disciplina a que iria se dedicar em São Paulo. Tornou-se grande amigo de Rivet, trazendo-o ao Brasil e traduzindo o seu livro As origens do homem americano. Com a ocupaçáo da França na Segunda Guerra Mundial, transferiu-se para Nova Iorque, onde trabalhou no Museum of Modern Art. Outra de suas atividades, a carreira de locutor na NBC, foi sustada a pedido da ditadura Vargas. Mesmo do exterior participou vivamente da derrubada dessa ditadura, tendo efetuado uma secreta e rocambolesca viagem ao Brasil, quando se entrevistou com o general Eurico Gaspar Dutra, condestável de Vargas.

Em fins de 1945, de volta ao país após a restauração democrática conseguiu, na interventoria Macedo Soares, dois feitos de grande importância: a criação, junto à Casa Civil do interventor, do Instituto de Pré-História precipuamente devotado ao estudo dos sambaquís, e o Instituto Paulista de Oceanografia, junto à Secretaria da Agricultura. Ambos os institutos passaram à Universidade de Sáo Paulo em 1962, o último já com seu nome definitivo, Instituto Oceanográfico. Para dirigir este Instituto, ainda na Secretaria da Agricultura, conseguiu trazer da França o professor Besnard, recomendado por Rivet.

Atento aos movimentos político, social e cultural do país, o nome de Paulo Duarte era-me já conhecido havia muitos anos, mas somente viemos a travar relaçóes pessoais por ocasião da passagem do Instituto de Pré-História para a Universidade de São Paulo, evento do qual pretendo ter participado.

$\mathrm{Na}$ ocasiáo, o governo do estado estava prestes a ser entregue 
novamente a Adhemar de Barros e isso significaria grande perigo à sobrevivência do Instituto de Pré-História, anexo à Casa Civil. A razão era que Paulo Duarte havia combatido duramente o governador, em vias de tomar posse, nos rumorosos casos dos Cheprolets e da Urma Marajoura, contribuindo para que, condenado pela Justiça, Adhemar se refugiasse na Bolívia. Era certo, pois, que como represália o novo governador poderia até extinguir o Instituto de Pré-História. Nesse tempo, fui visitado em meu gabinete por duas ex-alunas que trabalhavam no Instituto de Pré-História - uma delas a hoje famosa Niede Guidon -, às quais fiz ver o perigo a que ficaria exposto o Instituto com Adhemar no

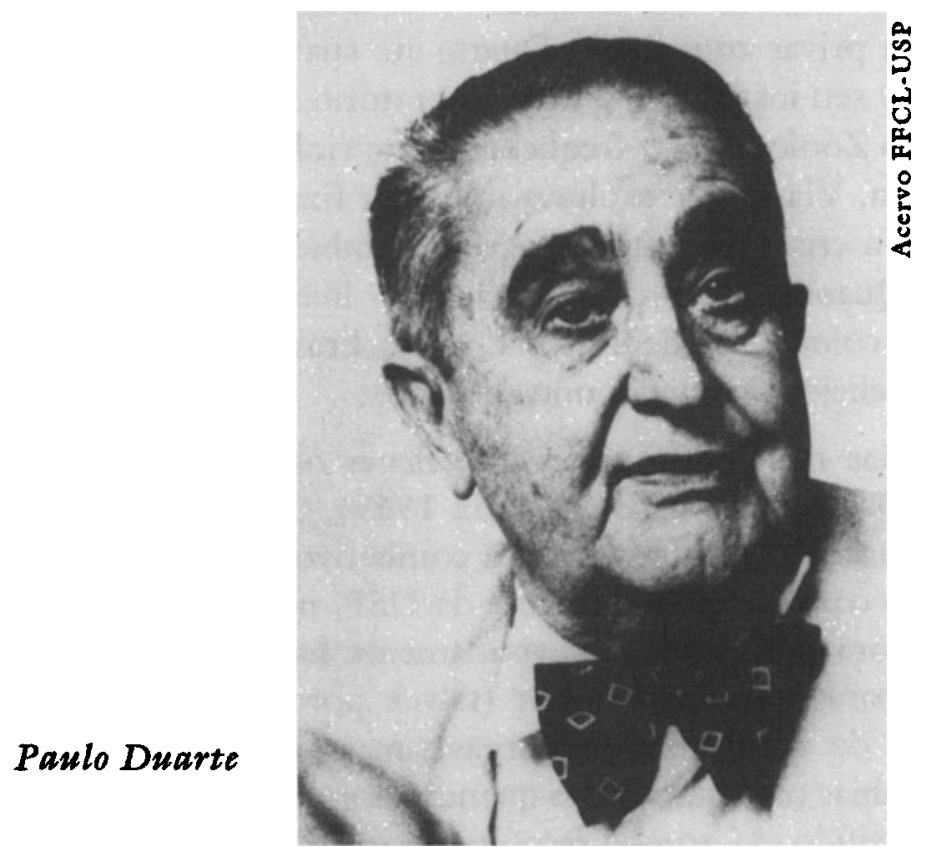

governo. Elas teriam alertado Paulo Duarte, que imediatamente iniciou as articulaçóes fora e dentro de Universidade para trazer o Instituto de Pré-História da Casa Civil para a USP, aproveitando-se de que, na ocasião, o Instituto Oceanográfico manobrava no mesmo sentido. Consumada a transferência, algum tempo depois Paulo Duarte procurou-me no Departamento de Fisiologia alojado no Edifício Zoologia - hoje Ernesto Marcus -, no campus, para me agradecer pelo empenho na preservaçáo do Instituto de Pré-História. Data dessa época (1962) o início de uma longa amizade que terminou apenas com seu falecimento em 23 de março de 1984. Na ocasião, após termos conversado bastante, perguntei inopinadamente a Paulo Duarte se queria conhecer o professor Paulo Sawaya, chefe do Departamento, com quem havia se desa- 
vindo pelas colunas da Anbembi a propósito de am mal entendido. Como ele se mostrou favorável, dirigi-me à sala do professor Sawaya, inquirindo-o sobre se ele também queria conhecer Paulo Duarte que, naquele momento, achava-se no meu gabinete. Diante da anuência de Sawaya, conduzi Paulo Duarte até ele e deixei-os a sós, dialogando. $O$ resultado desse diálogo foi que Sawaya acabou por oferecer a Paulo Duarte dependências ociosas no seu Departamento para abrigar o instituto recém-transferido para a USP, sem a previsáo de local para sua instalação. Assim, o Instituto de Pré-História ficou longos anos no Departamento de Fisiologia.

Foi durante sua temporada no Departamento de Fisiologia que passei a privar com Paulo Duarte até sua aposentadoria punitiva pelo AI-5. O seu instituto e o meu laboratório ficavam no mesmo andar do Edifício Zoologia e ele freqüentemente vinha à minha sala para uma boa conversa. Via-se que exultava por estar finalmente na universidade que ajudara a criar, desfrutando agora o ambiente em que sempre desejara estar. Quando me presenteou com o livro Mário de Andrade por ele mesmo, colocou na dedicatória: "Para Erasmo Mendes, lembranças do nosso delicioso convívio universitárion.

Mas náo foram sempre de flores os tumultuosos anos em que Paulo Duarte ficou na USP (1962-1969). Como era de se esperar de seu temperamento inconformista e combativo, náo tardou em entrar em conflito com a cúpula dirigente da USP, nesse tempo, um tanto retrógrada para seu gosto. Desavisadamente havia aderido aos que conspiraram para derrubar Goulart (talvez porque o considerasse herdeiro político do arqui-inimigo Vargas), mas apenas se deu conta das más companhias com que andara quando os golpistas de 64 mostraram a que tinham vindo. Aí, tomou resoluta posiçáo contra a caça às bruxas que se instalou na USP e começou a se inteirar de que isso refletia a mentalidade algo tacanha, imobilista e compadresca que dominava a Universidade. Esse inconformismo com a situação da USP foi crescendo, até que em 11 de maio de 1965 deu a $A$ Gazeta uma contundente entrevista, em que se referiu à usual incompetência dos reitores, chamou de rinocerontes (animais míopes) a maioria dos catedráticos e clamou contra o terrorismo cultural que se instalava na USP, como corolário do golpe de 64. A reaçáo năo tardou. Em 26 de agosto, o professsor Buzaid, diretor da Faculdade de Direito, apresentou em sessão do Conselho Universitário uma moçáo da Congregaçáo dessa unidade de ensino em que, diante da prottroia vituperatipa de Paulo Duarte - que fazia parte do Conselho e estava presente - solicitava que se abrisse processo contra o diretor do Instituto de Pré-História. Após discussão da questáo, esta foi submetida à votaçáo - nominal, conforme proposta do professor Paiva 
e, apurada a mesma, dos 33 conselheiros presentes, apenas eu e o Assistente W. Colli - Paulo Duarte obviamente se abstido - votaram contra. $O$ inquérito correu em dependência da Faculdade de Direito; tão morosamente que Paulo Duarte teve que desengavetá-lo algumas vezes, pois estava ansioso para usar seu depoimento como arma de ataque. Tendo terminado, como se diria hoje, em pizza, Paulo Duarte coligiu material para escrever o seu conhecido $O$ processo dos rinocerontes. Mesmo estando processado, ele continuou na diretoria do Instituto de PréHistória até seu afastamento pelo AI-5.

Haveria ainda uma enormidade de fatos a contar a respeito de Paulo Duarte, mas isso ficará para seu eventual biógrafo. Aposentado, ele passou, enquanto a saúde permitiu, a receber os amigos no seu apartamento da rua Caconde. Aí, em agradáveis reunióes, a gente proseava e sorvia aos poucos um excelente conhaque posto em copos bojudos e de boca estreita que nós aquecíamos, revolvendo-os com as palmas das duas máos. E, entáo, Paulo recordava eventos passados, sua temporada em Paris, quando conviveu entre outros com Rivet, Buñuel e Picasso. Um homem que viveu intensamente a sua época.

Erasono Garcia Mendes é professor emérito da USP e integra a Mesa Editorial da revista Estudos Aparngados. 